\title{
Characteristics of burn injury and factors in relation to infection among pediatric patients
}

\begin{abstract}
Burn injury is one of the most common and devastating forms of trauma and a major health problem of pediatric morbidity and mortality worldwide. The risk of infection in pediatric burns is well-known. An observational checklist was used by the researcher to assess the patients' characteristics and factors related to burn injury and infection from 1037 pediatric patients. The observational data collection showed that $56.5 \%$ of patients were males. The highest risk groups for burn injury are preschool stages. The most frequent places for burns were home $97.5 \%$. The mechanism of burn includes scalds $72.5 \%$, flame $22.8 \%$, contact $2.1 \%$, electrical $1.8 \%$, chemical $0.8 \%$ and friction $0.2 \%$. The prevalence of infection was $23.4 \%$. Patients from flame burns more likely get infections $39.1 \%(\mathrm{p}=0.001)$. Other factors associated with infection such as degree of burns, extent of body burn surface and length of hospital stay. Regarding etiology of scald burn injury, hot water is a predominant cause of burn injury $78.99 \%$. There was a significant relation between Total Body Surface Area (TBSA) and mortality $p<0.001$. Patients with $>40 \%$ of TBSA has a high proportion rate for death $55.7 \%$. The majority of died patients caused by flame $65.6 \%$ and statistically highly significant $\mathrm{P}<0.001$. Infection and inhalation injury are the main factors related to death $37.7 \%$ vs. $58.0 \%$. From 748 positive samples, the most common found organism was MethicillinResistant Staphylococcus aureus (MRSA) 34.2\%, followed by Pseudomonas aerogenosa and Acienetobacter baumannii 16.7\%, 16.4\% respectively. Patients with greater mean TBSA and prolonged hospital stay more likely to get Gram-negative bacterial and fungal infections and highly statistically significant $p<0.001$. Many other studies are need to determine the epidemiology and factors related to microbiological infection among pediatric burn patients.
\end{abstract}

Keywords: pediatric, burn patient, nosocomial infection, tbsa \& mrsa
Volume I Issue $3-2017$

\author{
Kamal Jalal Rashid, Muhammed Babakir-Mina, \\ Dana Abdilmagid Abdilkarim \\ Technical College of Health, Sulaimani Polytechnic University, \\ Sulaimani, Kurdistan Region, Iraq
}

Correspondence: Muhammed Babakir-Mina, Technical College of Health, Sulaimani Polytechnic University, Sulaimani, Kurdistan Region, Iraq. Tel +964(0)7710213991,

Email m.babakir@yahoo.com

Received: March 18, 2017 | Published: April 06, 2017

\section{Introduction}

Burn is described as one of the leading causes of injury throughout the world, and is one of the most frequent causes of hospitalization. Burn is a major cause of morbidity and mortality, and it is the fourth most common type of trauma worldwide. ${ }^{1,2}$ Burn is a major issue on public health in terms of infection control and cost of treatment in both developing and developed countries, and burn in pediatric range from minor to severe injuries ${ }^{3}$ Injuries in pediatrics are predictable, avoidable and preventable., ${ }^{4,5}$ Burns from hot drinks, food, steam, or other hot liquids are common causes of burn injuries to young children compared to other burn injuries. ${ }^{2}$

Burn patients are at high risk for infection as a result of the nature of the burn injury itself, the immunocompromizing effects of burns, prolonged hospital stays, and intensive diagnostic and therapeutic procedures. Sepsis of burn wounds is a serious problem leading to death and is one of the most important factors determining the prognosis of burn disease. ${ }^{6-8}$ Burn wound infection is directly correlated to the extent of burn. It is related to impaired resistance from disruption of skin's mechanical integrity and generalized immune suppression. Non burned wound infection such as Pneumonia and Urinary Tract Infection (UTI) have become a more prominent cause of significant morbidity and mortality following the decline in invasive wound infection. ${ }^{9}$

The risk of burn injuries in children is higher when compared with adults. Burns in pediatric age group are generally accidentally occurring. Many of these injuries occur in the home where young children spend most of their time. There are many reasons for burn in children such as less perception of dangerous situation, recklessness and less ability to react properly in dangerous situation. ${ }^{10}$

Local effects are usually ranging from partial or full thickness skin burn to the destruction underling subcutaneous tissue and bone. While systemic effects cause cell death and it is conducted into surrounding tissue due to increasing capillary permeability and loss of fluid from the intravascular space and potentially fatal systemic inflammatory response syndrome can be delayed for several hours after burn. ${ }^{11}$

According to National Healthcare Safety Network (NHSN), nosocomial infections (NI) are localized or systemic conditions caused by adverse reaction to the presence of infectious agent or its toxins. Nosocomial infections are those infections that develop during hospitalization and are neither present nor incubated at the time of patient's admission. It represents a major problem in health care facilities, resulting in prolonged hospital stays, substantial morbidity and mortality, and excessive costs. The typical incubation period for bacterial hospital-acquired infections (HAIs) is usually $\geq 48$ hours after admission. ${ }^{12,13}$

Large open wound areas that containing necrotic tissue make burned patients more susceptible to infection. Burn patients are also need to stay in high-risk intensive care units for prolonged periods of time. ${ }^{14}$ The degree or amount of contamination is proportional to the size of the open wound. ${ }^{15}$ 
Source of organisms are found in the patient's own endogenous, from exogenous in the environment, and from healthcare personal or parents. The most common type of Nosocomial infections in burned children's is bloodstream infections, pneumonia, UTI, skin and surgical site infections. Organisms such as gram-negative bacteria, gram-positive bacteria, viral and yeast/fungal are the main causes of burn nosocomial infections. ${ }^{16,17}$

Burn centers and burn hospitals should routinely determine and observe the specific pattern of burn microbial infection, time-related changes in the predominant microbial flora of the burn patient, the antimicrobial susceptibility profiles of microorganisms implicated in burn wound infections in a given time period, and trends in the nosocomial spread of these agents. ${ }^{18,19}$

\section{Methods}

\section{Study design and setting}

The study was conducted at Sulaimani Burn and Plastic Surgery Hospital, Kurdistan Region, Iraq. The data collection was collected from the previous medical records of 1307 pediatric burn patients less than 15 years of age who had sustained burn injury and admitted to hospital for receiving medical care to describe the magnitude, clinical presentation and outcome of pediatric burn injuries and infection from January 2010 - December 2015. Data generated from this work were tabulated into Microsoft excel sheets and uploaded to SPSS (Statistical Package for Social Sciences) version 22.0 software. Percentage / correlating was used for measure and analysis Chi-square $\left(\chi^{2}\right)$ test was used to test for significance of associations between the predictor and outcome variables in the categorical variables to find an outcome related to health issues. T-test used for comparison two means. Statistical comparison of microbial isolates and their resistance pattern was done. P-value of $<0.05$ was considered as statistically significant cutoff. In this study the ethical interfere with the legality which applied on patients and their parents who are admitted.

\section{Sample collection}

Clinical samples were collected through surface swabs, tissue, blood, and urine. Multiple samples from several areas of the burn were collected in order to obtain the most accurate assessment. To study burn wound colonization and infection, swabs were taken from open burn wounds preferably from upper and lower extremities avoiding oral, genital, scalp, anterior and posterior trunk, buttock, and anal regions. Burn wound swabs were taken initially on admission (patients with 48hours, 5day, second week, third week and fourth week of stay were included in the study). They were taken before dressing changes and before administration of antibiotics wherever possible. Wound swabs were also taken whenever there were clinical signs of grafted skin infections. Urine cultures were performed once per week for those with indwelling urinary catheters and on request for those with signs and symptoms of UTI. Culture and antibiotic sensitivity test undertaken at the center microbiological laboratory department inside the hospital. ${ }^{18}$

\section{Microbiological investigation}

The swabs were dipped in Stuarts transport medium, and then inoculated on selective and differential medium (Manitol salt agar), enrich medium (blood agar). The isolates were identified using conventional identification techniques after incubation for 18-48 hours at $37^{\circ} \mathrm{C}$ [20]. Positive cultures were sub cultured on blood agar and MacConkey agar, as per routine bacteriological guidelines. API (Analytical Profile Index) 20E system was used to identify the isolated gram-negative bacteria. While gram stains, catalase test, hemolysis on blood agar, coagulase and other tests were used to identify gram-positive bacteria submitted to identification tests. Also latex agglutination test were used as a confirmation stages of investigation. (BioMerieux SA,Lyon, France). ${ }^{21}$

Small filter paper disks $(6 \mathrm{~mm})$ impregnated with a standard amount of antimicrobials were placed onto an agar plate to which bacteria have been swabbed by a bacterial suspension using distilled water comparable to $0.5 \mathrm{McF}$ arland turbidity standard. After 15 minutes of inoculation, the antimicrobial containing discs are applied to the agar with sterile forceps pressed firmly to ensure contact with the agar and then the plates of Muller Hinton Agar were incubated overnight, and the zone of inhibition of bacterial growth was measured for Gram-positive and Gram-negative bacteria. Then the result will be calculated as describe elsewhere. ${ }^{22}$

\section{Results}

\section{Demographic characteristics of patients}

A total of 1307 pediatric burn patients were studied, of which 741 $(56.5 \%)$ patients were males and $566(43.5 \%)$ were females. Children in kindergarten stage (2-6 years of age) makes the highest proportion of the patients $547(41.9 \%)$. According to the place of injury, most frequent burns occurred at home $1274(97.5 \%)$ followed by work 21 $(1.6 \%)$, picnic $7(0.5 \%)$ and then other locations $5(0.4 \%)$. In addition the majority of burn injury occurred in Spring 362 (27.7\%) and 352 $(26.9 \%)$ in winter, but the frequency of burn injury decreased in Summer $298(22.8 \%)$ in and $295(22.6 \%)$ in autumn (Table1).

Table I Demographic characteristic of patients. (Total No.=|307)

\begin{tabular}{lll}
\hline Demographic characteristic & No. (\%) & Statistical test analysis \\
\hline Sex & $74 \mid(56.5)$ & $\chi 2=0.52, \mathrm{Idf}, \mathrm{p}=0.4$ \\
Male & $566(43.5)$ & \\
Female & \\
Age group & $453(34.7)$ & \\
$<2$ & $547(41.9)$ & \\
6-Feb & $307(23.5)$ & \\
$>6$ & & \\
Place of burn injury & $1274(97.2,2 \mathrm{df}, \mathrm{p}=0.00 \mathrm{I}$ \\
Home & $21(1.6)$ & \\
Work & $7(0.5)$ & \\
Picnic & $5(0.4)$ & \\
Other locations & \\
Seasonal of injury & $352(26.9)$ \\
Winter & $362(27.7)$ \\
Spring & $295(22.8)$ \\
Summer & $298(22.6)$ \\
Autumn & $1307(100)$ \\
Total &
\end{tabular}




\section{Mechanism and place of burn injury}

The study showed that scald burns were more common in preschool children (421 out of 947, 44.5\%) followed by flame (110 out of $296,36.9 \%$ ), while majority of flame burns occurred in school children; more than 6 years of age (156 out of 298, 52.3\%) and statistically significant $p<0.001$. (Table 2 ) The study showed that scald burns was the most frequent causes of burn injury, 947 (72.5\%) followed by flame, contact, electrical, chemical, and friction 298 (22.8\%), $27(2.1 \%), 23(1.8 \%), 10(0.8 \%)$, and $2(0.2 \%)$, respectively. There were significant differences of infection in terms of mechanism of burn injury; flame burns more likely to be infected followed by Electrical and scald $(39.1 \%, 31.9 \%, 20.3 \%$, respectively) $\mathrm{p}=0.001$ (Table 3). Regarding etiology of scald burn injury, among 947 cases, the majority of cases were burned by hot water $78.99 \%$ followed by soup $6.86 \%$ and few cases caused by hot sugar $0.08 \%$ (Table 3 ).
Table 2 Comparison of the mechanism of burn in the different age group

\begin{tabular}{|c|c|c|c|}
\hline \multirow[t]{2}{*}{ Mechanism of burn } & \multicolumn{3}{|c|}{ Age group No. (\%) / years } \\
\hline & $<2$ & $2-6$ & $>6$ \\
\hline Scald & 406 (42.9) & $421(44.5)$ & $120(12.6)$ \\
\hline Flame & $32(10.8)$ & $110(36.9)$ & $156(52.3)$ \\
\hline Electrical & I (4.3) & $3(13.1)$ & $19(82.6)$ \\
\hline Contact & II (40.7) & $10(37.0)$ & $6(22.3)$ \\
\hline Chemical & $3(30.0)$ & $2(20.0)$ & $5(50.0)$ \\
\hline Friction & 0 & I (50.0) & I (50.0) \\
\hline Statistical test value & \multicolumn{3}{|l|}{$\mathrm{p}<0.00 \mathrm{la}$} \\
\hline
\end{tabular}

Table 3 Distribution of mechanism of burn and in relation to infection. (Total No. $=1307$ )

\begin{tabular}{lllll}
\hline Mechanism of burn & Total & Not infected & Infected & Statistical test \\
& No. $(\%)$ & No. (\%) & No. (\%) & value \\
\hline Scald a & $947(72.5)$ & $750(79.2)$ & $197(20.8)$ & $\chi 2=21.6,5 \mathrm{df}, \mathrm{p}=0.00 \mathrm{I}$ \\
Flame & $298(22.8)$ & $203(60.9)$ & $9(31.9)$ \\
Electric & $23(1.8)$ & $14(68.1)$ & $3(1 \mathrm{l})$ & $2(20.0)$ \\
Contact & $27(2.1)$ & $24(88.9)$ & $8(80.0)$ & $0(0.0)$ \\
Chemical & $10(0.8)$ & $2(100.0)$ & $306(23.4)$ \\
Friction & $2(0.2)$ & $1001(76.3)$ &
\end{tabular}

${ }^{a}$ A total of 947 scald cases; $78.99 \%$ caused by hot water, $6.86 \%$ by hot soup, $6.76 \%$ by hot oil, $4.54 \%$ by hot tea, $2.77 \%$ by hot milk, and $0.08 \%$ by hot sugar.

Degree of burn (depth), measurement burn size, and hospital stays of patients

Children with second degree of burn were the majority of burns $949(72.6 \%)$ and children who sustained third and mix degree burns were $358(27.4 \%)$. Third and mix degree of burn were more likely to be infected (131 out of $358,36.6 \%)$ than second degree burn (175 out of $949,18.4 \%$ ) $p<0.001$ (Table 4). The frequency of Patients with TBSA burnt of $<20 \%$ were making the majority of the cases 1075 $(82.2 \%)$, followed by $20-40 \% 184(14.1 \%)$. The frequency become least with increasing body burnt $\%$. Patients with TBSA burnt of 20$40 \%$ were more likely to have infection compared to patient with TBSA $\%$ burnt of $<20 \%$ and $>40 \%(p<0.001)$ (Table 4$)$.

Table 4 Distribution of depth (degree) and TBSA burnt in relation to infection. (Total No.=1307)

\begin{tabular}{llllll}
\hline & & $\begin{array}{l}\text { Not infected } \\
\text { No. (\%) }\end{array}$ & $\begin{array}{l}\text { Infected } \\
\text { No. }(\%)\end{array}$ & $\begin{array}{l}\text { Total } \\
\text { No. (\%) }\end{array}$ & Statistical test value \\
\hline Degree of burn & Second & $774(81.6)$ & $175(18.4)$ & $949(72.6)$ & $\chi 2=44.76, I \mathrm{df}, \mathrm{p}<0.001$ \\
& Third and mix & $227(63.4)$ & $131(36.6)$ & $358(27.4)$ & \\
TBSA group & $<20$ & $894(83.2)$ & $181(16.8)$ & $1075(82.2)$ & $\chi 2=|57.52,2 \mathrm{df}, \mathrm{p}<0.00|$ \\
& $20-40$ & $76(41.3)$ & $108(58.7)$ & $184(14.1)$ & \\
& $>40$ & $31(64.6)$ & $17(35.4)$ & $48(3.7)$ & \\
\hline
\end{tabular}

Mean TBSA was 14.06 (95\%CI 13.40-14.72) and Mean Hospital stay/days was 7.6 (95\%CI 7.21-7.98). Patients with higher TBSA burnt were found to be more likely to develop infection and the relation was found to be statistically significant $p<0.001$. Also patients with infection had a longer duration of stay in the hospital as compared to those not infected and this comparison was found to be statistically significant $\mathrm{p}<0.001$ (Table 5).

\section{Mortality}

The study shows 1246 (95.3\%) cases are survived and 61 (4.7\%) 
cases were died. The mean TBSA of survived patients was 12.39 (95\%CI 11.92-12.86) and died patients was 48.22 (95\%CI 42.51 53.92). There was a significant relation between TBSA and mortality $\mathrm{p}<0.001$. Patients with $>40 \%$ of TBSA marked high proportion rate for death $55.7 \%$ (Table 6 ). The majority of died patients caused by flame was $40(65.6 \%)$, followed by scald $18(29.5 \%)$, electric 2 $(3.3 \%)$ and contact $1(1.6 \%)$. Mortality rate from flame burn was highly significant $\mathrm{P}<0.001$. A total of 1001 not infected patients, 963 $(77.3 \%)$ were survived and 38 (62.3\%) were died. From 306 infected patients, 283 (22.7) were survived and 23 (37.7\%) were died $\mathrm{p}=0.007$ (Table 7).

From 38 of non-infected died patients, the highest percent of died were $71.1 \%$ with $>40 \%$ of TBSA. Patients with $<20 \%$ of TBSA has $100.0 \%$ of inhalation injury followed by $20-40 \%$ of TBSA $80.0 \%$ and $>40 \%$ TBSA $48.1 \%$ (Table 8 ).

Table 6 Distribution of patients TBSA according outcome. (Total patient=1307)
Table 5 Comparison of infected and non-infected burn patients according to TBSA\% burnt and hospital stay in days. (Total patients $=1307$ )

\begin{tabular}{|c|c|c|}
\hline & $\begin{array}{l}\text { Mean tbsa } \\
(95 \% \mathrm{Cl})\end{array}$ & $\begin{array}{l}\text { Mean hospital stay (days) } \\
(95 \% \mathrm{Cl})\end{array}$ \\
\hline Total mean & 14.06 (13.40-|4.72) & $7.6(7.21-7.98)$ \\
\hline Not-Infected & $12.4 \mid(11.68-13.14)$ & $5.58(5.29-5.86)$ \\
\hline Infected & 19.48 (I8.13-20.84) & $14.20(13.12-15.28)$ \\
\hline Mean differences & 7.07 & 8.62 \\
\hline Statistical test value & $t=9.1, p<0.001$ & $\mathrm{t}=21.5, \mathrm{p}<0.001$ \\
\hline
\end{tabular}

\begin{tabular}{|c|c|c|c|c|c|}
\hline \multirow[t]{2}{*}{ Outcome } & \multirow[t]{2}{*}{ No. (\%) } & \multicolumn{3}{|c|}{ TBSA group No. (\%) } & \multirow{2}{*}{$\begin{array}{l}\text { TBSA } \\
\text { Mean }(95 \% \mathrm{Cl})\end{array}$} \\
\hline & & $<20$ & $20-40$ & $>40$ & \\
\hline Survival & $1246(95.3)$ & $1069(85.8)$ & $163(13.1)$ & $14(1.1)$ & $12.39(11.92-12.86)$ \\
\hline Died & $61(4.7)$ & $6(9.8)$ & $21(34.5)$ & $34(55.7)$ & $48.22(42.5 I-53.92)$ \\
\hline Statistical test value & - & $\mathrm{p}<0.00 \mathrm{Ia}$ & & & $\mathrm{p}<0.00 \mathrm{Ib}$ \\
\hline
\end{tabular}

Table 7 Mechanism of burn injuries and infection in relation to mortality. (Total patients=1307)

\begin{tabular}{lllllllll}
\hline Outcome & \multicolumn{2}{l}{ Mechanism of burn } & & & & & Not infected & Infected \\
\cline { 2 - 7 } & Scald & Flame & Electric & Contact & Chemical & Friction & No (\%) & No. (\%) \\
& No. (\%) & No. (\%) & No. (\%) & No. (\%) & No. (\%) & No. (\%) & & \\
\hline Survivors & $929(74.6)$ & $258(20.7)$ & $21(1.7)$ & $26(2.0)$ & $10(0.8)$ & $2(0.2)$ & $963(77.3)$ & $283(22.7)$ \\
Died & $18(29.5)$ & $40(65.6)$ & $2(3.3)$ & $1(1.6)$ & 0 & 0 & $38(62.3)$ & $23(37.7)$ \\
Test value & $\chi 2=92.7,5 \mathrm{df}, \mathrm{p}<0.001$ & & & & & $\chi 2=7.29$, Idf, $\mathrm{p}=0.007$ \\
\hline
\end{tabular}

Table 8 Distribution died burn patients with TBSA burnt and Inhalation injury. (No=38 died patients)

\begin{tabular}{|c|c|c|c|}
\hline \multirow[t]{2}{*}{ TBSA\% } & \multicolumn{2}{|c|}{ Inhalation injury No. (\%) } & \multirow[t]{2}{*}{ Total } \\
\hline & Yes & No & \\
\hline$<20$ & I (I00.0) & 0 & I (2.6) \\
\hline $20-40$ & $8(80.0)$ & $2(20.0)$ & $10(26.3)$ \\
\hline$>40$ & I3 (48.I) & |4 (5।.9) & 27 (7I.I) \\
\hline Total & $22(58.0)$ & $16(42.0)$ & $38(100)$ \\
\hline
\end{tabular}

\section{Locations of body burn positive samples}

The study included 748 of positive cultures from 306 infected patients. Number of positive samples per patients ranged from 1 to 10 samples. $49.3 \%$ had one sample, $30.7 \%$ had two samples, $7.3 \%$ had three positive samples, and $12.7 \%$ with more than three samples. Majority of positive sample results were in the burn wounds 688 $(92.0 \%)$, followed by blood $41(5.5 \%)$, and urine $19(2.5 \%)$ (Table 9$)$.
Table 9 Distribution of positive sample according to body parts. (Total positive samples $=748$ )

\begin{tabular}{llll}
\hline \multicolumn{2}{l}{ Location of positive cultures } & No. & (\%) \\
\hline Wound positive samples & Upper limb & 122 & -16.3 \\
& Lower limb & 285 & -38.1 \\
& Anterior trunk & 116 & -15.5 \\
& Posterior trunk & 85 & -11.4 \\
& Head \& neck & 41 & -5.5 \\
& Buttock \& genital & 39 & -5.2 \\
Non wound positive samples & blood culture & 41 & -5.5 \\
& urine culture & 19 & -2.5 \\
\hline Total & & $\mathbf{7 4 8}$ & -100
\end{tabular}

With regard to the anatomical location of burn wound injuries, the lower limb was the most frequently involved area with positive 
samples 285 (38.1\%), followed by upper limb $122(16.3 \%)$, anterior trunk $116(3801 \%)$, posterior trunk $85(11.4 \%)$, head \& neck 41 (5.5\%), and buttock \& genital 39 (5.2\%) (Table 9).

\section{Microbiological finding:}

From the total of 748 positive samples, the most common organism found was gram-positive bacteria MRSA 256(34.2\%), followed by gram-negative $P$. aeruginosa and A. baumannii $125(16.7 \%), 123(16.4 \%)$ respectively. Other organism included Non MRSA S. aureus, K. pneumoniae, E. cloacae, E. coli, Proteus species,
S. epidermidis, CoNS and fungi (Candida albicans) $86(11.5 \%)$, $78(10.4 \%), 39(5.2 \%), 17(2.3 \%), 8(1.1 \%), 8(1.1 \%), 3(0.4 \%)$ and $5(0.7 \%)$ respectively. The mean TBSA of burn was proportional in fungal infection $27.4(95 \% \mathrm{CI} 11.29-43.51)$ and gram-negative bacterial infections $25.49(95 \%$ CI 24.19-26.79) as compared with gram-positive bacterial infection $19.92(95 \%$ CI $18.70-21.14) \mathrm{p}<0.001$. Similarly we found that the mean hospital stay in fungal infection $24.4(95 \mathrm{CI}$ 20.41-28.38) and gram-negative bacterial infection $20.62(95 \% \mathrm{CI}$ $19.45-21.79)$ that is higher than gram-positive bacterial infection 16.54(95\%CI 15.53-17.56) $\mathrm{p}<0.001$ (Table 10).

Table 10 Distribution type of organisms, association with TBSA and hospital stays. (Total No. $=748$ )

\begin{tabular}{|c|c|c|c|c|}
\hline \multicolumn{2}{|c|}{ Type of organisms } & No. (\%) & $\begin{array}{l}\text { TBSA } \\
\text { Mean }(95 \% \mathrm{Cl})\end{array}$ & $\begin{array}{l}\text { Hospital stay } \\
\text { Mean }(95 \% \mathrm{Cl})\end{array}$ \\
\hline \multirow[t]{5}{*}{ Gram-positive } & MRSA & $256(34.2)$ & $21.5(20.06-22.95)$ & $18.73(17.53-19.93)$ \\
\hline & S. aureus & $86(11.5)$ & $16.32(14.01-18.63)$ & $10.78(9.27-12.27)$ \\
\hline & S. epidermidis & $8(1.1)$ & $11.21(7.50-14.93)$ & $8.88(4.44-13.30)$ \\
\hline & CoNS & $3(0.4)$ & $11.33(0.13-22.53)$ & $15.33(-2.1 \mid-32.78)$ \\
\hline & Total & $353(47.2)$ & $19.92(|8.70-2| . \mid 4)$ & $16.54(15.53-17.56)$ \\
\hline \multirow[t]{7}{*}{ Gram-negative } & P. aeruginosa & $125(16.7)$ & $25.67(23.37-27.98)$ & $20.33(18.19-22.68)$ \\
\hline & A. baumannii & $123(16.4)$ & $26.03(23.63-28.45)$ & $20.78(18.78-22.68)$ \\
\hline & K. pneumonia & $78(10.4)$ & $26.03(23.21-28.85)$ & $20.3 \mid(|7.69-22.9|)$ \\
\hline & E. cloacae & $39(5.2)$ & $22.29(17.91-26.68)$ & 23.49 (I8.68-28.28) \\
\hline & E. coli & $17(2.3)$ & $25.17(\mid 8.44-31.98)$ & $16.47(12.18-20.75)$ \\
\hline & Proteus species & $8(1.1)$ & $25.22(16.65-33.80)$ & $20.63(9.66-31.58)$ \\
\hline & Total & $390(52.1)$ & $25.49(24.19-26.79)$ & $20.62(19.45-21.79)$ \\
\hline Fungi & Candida albicans & $5(0.7)$ & $27.4(|| .29-43.5 \mid)$ & $24.4(20.41-28.38)$ \\
\hline $\mathrm{p}$ - value & & - & $\mathrm{p}<0.00 \mathrm{Ia}$ & $p<0.00 \mathrm{la}$ \\
\hline
\end{tabular}

\section{Discussion}

Age

In the current study children in preschool stage (2-6 years of age) shows high proportion of burn injury than other age groups (Table 1). This finding is nearly consistent to the previous studies which are done in Iraq, ${ }^{23}$ and in Brazil. ${ }^{24}$ It is also supported by the WHO injury reports stating that children under 5 years are at the highest risk of burn injuries. ${ }^{25}$ Nevertheless, many studies around the world have reported that infants (less than 2 years old) are the most frequent groups injured by burning, such as in China, ${ }^{26} \mathrm{USA},{ }^{27} \mathrm{India}^{28}$ and Ghana. ${ }^{29}$ This is probably because these children in our country spend most of their times at home near different types of heating and cooking equipment's. Another fact may be due to the hyper mobility of children and lack of judgment which makes them difficult to control.

\section{Sex}

In the current study males $(56.5 \%)$ were more affected to burn injury than females $(43.5 \%)$ (Table1). It is nearly consistent with many studies in low-income and middle income countries such as $60 \%$ in Iran,${ }^{30} 53.2 \%$ in Turkey,${ }^{31} 50.9 \%$ in Pakistan. ${ }^{32}$ Also studies from high- income countries is nearly reported the same proportions; $60.3 \%$ in Saudi Arabia, ${ }^{33} 62 \%$ in Japan, ${ }^{34} 66 \%$ in UK, ${ }^{35} 56 \%$ in Morocco $^{36}$ and $67.2 \%$ in USA..$^{37}$ The high percent of male burn injured in our study could be due to increased exposure to activities, males are more active than females that produce injuries and the pattern of more risk taking and rougher players than females. So, a previous study has the same explanation. ${ }^{38}$

\section{Place of injury}

Our study showed that more of pediatric burn injuries happened at home (Table1). This finding nearly in accordance with the previous studies which revealed that most of burn injuries were at home. ${ }^{39,40}$ This is because of in our society children spend more of their times at home rather than other places.

\section{Mechanisms of burn injury}

Our study showed that scald burns were the most frequent cause of burn injuries (Table 3). Similarly the various observations had reported that scald burns are the most common cause of burn injuries. ${ }^{29,41-44}$ This can be explained that children especially infants and preschool children stay with their parents or caregiver at home, and would 
probably be left playing indoor around the kitchen environment. In our study scalds were commonly caused by hot or boiling water (Table 3), which is consistent with the finding of the previous study. ${ }^{45}$ This may be explained that hot liquids are of high importance at our homes and most frequently used in many life aspects.

In our study flame burns were the second cause of burn injury $22.8 \%$ (Table 3). Many of studies around the world have similar results $^{36,43,44,46,47}$ Equipment and products were more responsible for flame burn diverse, but the most important of them were home equipment's used for cooking or heating. Another factor contributing to the risk of these cylinders usually places it near the cooker equipment's inside the kitchen, especially in old buildings.

We found that flame burn injuries were more prevalent in children aged more than six years (Table 2), which is in agreement with the finding of the study conducted in Tanzania. ${ }^{39}$ This may be related to the raise of physical mobility and social independence in our country of older children especially girls for preparing foods and other works related cooking and lighting fires. Also this difference is highly statistical significant $\mathrm{p}<0.001$.

In our study patients with flame burns more likely to be infected than other burns with statistically significant $\mathrm{p}=0.001$ (Table 3 ). Similar findings showed by Abbas Atiya $\mathrm{H}^{48}$ The main reasons for this finding may be due to production of large and deepest burn wound surface which is a protein-rich environment consisting of excessive necrotic tissue (eschar) that provides more favorable niche for microbial colonization and proliferation, this explanation has been currently supported by many of scientific researcher studies. ${ }^{18,49-51}$

\section{Seasonal of injury}

The study showed that majority of burn injury occurred in cold season especially in winter comprising all burn (Table 1).This finding agree with the other previous studies..$^{23,52}$ This is because of using kerosene-operated space-heating equipment in houses, especially in cold seasons in our city. Sometimes families put this equipment around seats and it drives to cause burn injury.

\section{Degree of burn (depth)}

This study revealed that majority of burn injuries with second degree of burn (Table 4). This finding is nearly in agreement with the other previous studies. ${ }^{53,54,26,55}$ But another study showed that the majority of burn patients admitted have the third degree of burn injuries ${ }^{56}$ For this reason longer period of burn exposure results in a potential longer time of contact with body surface, resulting in degree (depth) of burn.

In our study, patients who have third and mix degree of burn more likely to be infected as compared with other second degree of burn patients, this is highly statistical significant $p<0.001$ (Table 4). This is in agreement with the study has done by Larry Kramer for third degree of burn and infection. ${ }^{57}$ This may be due to the loss of more parts of skin and layers under skin which play an important role in protecting the body against infection and act as a barrier that prevent microbes from entering the body. ${ }^{18}$

\section{TBSA burnt}

In this study majority of TBSA burnt patients were less than $20 \%$ (Table 4). This finding is consistent with a study conducted in Israel. ${ }^{58}$ This variation of TBSA burnt percent is probably due to variations in distribution of the mechanism of burn injury. As well as severity and amount of causative agents indicated to produce variation of TBSA burnt percent.

We observed that patients with TBSA burnt $20-40 \%$ were more likely to be infected which accounted $58.7 \%$ and highly statistical significant $\mathrm{p}<0.001$ (Table 4). This finding is similar to the study done by Church, D. and his coauthors. ${ }^{18}$ This could be due to increasing body surface area which lets organisms to invade body and loss of more epithelium skin covering tissues which is a good indicator to survive and lets pathogens to colonize easily. ${ }^{59}$ Other reasons for this finding may be due to delay excision which increase the reservoir of bacteria made up by the collective burn wound surfaces of patients in a burn management, which is mentioned by Mayhall, C.G. ${ }^{60}$ However, in our study the proportion of infection decreased with increasing TBSA burnt when more than $40 \%$ which accounted $35.4 \%$ (Table 4 ). This is because of greater TBSA burnt percent has a good independent risk factor for patient to die before infected with organisms. This is Similar to a study done by Rosanova, M.T. and his coauthors in Argentina on risk factor for mortality in burned children. ${ }^{61}$

\section{Hospital stays of patients}

In the current study, the mean hospital stay was 7.6 days (Table 5). This result nearly in accordance to the previous studies were done in pediatric burn wards. ${ }^{3,30,62-64}$ In our study the mean hospital stay was statistically significant and greater in patients with infection $(14.20$ days) rather than in patients with no infection (5.58 days) $\mathrm{p}<0.001$ (Table 5). This result is in consistent with a study done in Spain, ${ }^{65}$ also another French study is agree with the above finding. ${ }^{9}$ More prolonged of hospital stay enhance the microbes to colonize and cause infection in burn patients. In addition, type and extent of wound, as well as the therapeutic procedure for management of organisms, debridement wound, skin grafting, and blood transfusion are other factors which related to the colorizations, this explanation has currently supported by a previous study. ${ }^{66}$

\section{Microbiological finding}

In our study a total of 1307 patients, almost 306 (23.4\%) of admitted patients (Table 1) had developed infections and the most common developed infection in the burning patient was wound infection (Table 9). This finding is in agreement with the other previous studies. ${ }^{32,67-69}$ But in the study conducted by Behzadnia $\mathrm{S}$ et al. ${ }^{62}$ showed that the rate of nosocomial infection in burn patients is more developed in blood stream. ${ }^{62}$ Burn patients will facilitate wound infection which is a serious complication occurs in sub-acute period following burn injury. ${ }^{69}$

A total of 748 positive samples, Number of positive samples per patients ranged from 1 to 10 samples, we found that the highest proportion of positive samples were gram-negative bacteria followed by gram-positive bacteria and few cases of fungi (Table 10). Our result in accordance with the previous study conducted by Mayhall, C.G. in USA. ${ }^{60}$ This finding has several interpretations; first, gram-negative organisms are major determinant of morbidity. ${ }^{32}$ Second, endogenous gram-negative bacteria come from the patient's gastrointestinal flora and rapidly colonize the burn wound surface after injury. On the other hand, delaying burn wound excision increases bacterial load, especially gram-negative and supports the rationale of early burn wound excision. Surgical excision decreases an average of 102 organisms per gram of tissue in both the early and delayed excision groups for gram-negative infection this is mentioned by Barret JP \& DN Herndon. ${ }^{49}$ 
In our study a total of 748 positive samples, among gram-positive infections; the first common isolated bacteria were MRSA $34.2 \%$ (Table 10). This is in consistent to other previous studies in pediatric burn wards. ${ }^{70-72}$ More recently, a 20 - years review of the changes in bacterial isolates from pediatric burn wounds and their antibiograms in Europe showed that MRSA remain the most frequent gram-positive pathogen. ${ }^{73}$ The prevalence of MRSA is various in clinical samples of pediatric burn patients as the result of distribution of Panton-Valentine Leukocidin (PVL) gene of the bacteria, Staphylococcal Cassette Chromosome mec (SCCmec) types and antibiotic resistant genes of the MRSA isolates. The disruption of the normal skin barrier and the immune compromised status make burn an easy target for MRSA colonization. Additionally, using various types of penicillin too much without changing and self uses of antibiotic randomly are risks for development of MRSA colonization in which supported by Branski, L.K., et al. ${ }^{68}$ On the other hand, gram-positive bacterial infection, especially MRSA comes from the patient's endogenous skin flora or the external environment predominantly colonizes the burn wounds. ${ }^{6}$ In spite of that ,children's parent need to mind the most because they cannot stand the pain, so this should make the mother to emotionally take care of her child, hug him/her be very near to her child, and bring $\mathrm{him} / \mathrm{her}$ things (toys) to the child busy to forget about his/her pain or wound. These all lead to transmission of microbes to the child quickly specifically MRSA; because it is found in a high rate on these out ward things which are not censored by the hospital.

In our study the second common isolated organism was $P$. aeruginosa $16.7 \%$ (Table 10). This is in contrast to other studies which are shown that a Pseudomonas bacterium was the most common pathogen in pediatric burn patients. ${ }^{32,62,74}$

The incidence of $P$. aeruginosa infection in the pediatric burn wards may be due to the fact that this bacterium thrives in a moist environment, and its ability to resist killing by more of antimicrobials. The minimal nutritional requirements of Pseudomonas, its ability to grow in distilled water and its tolerance to a wide variety of physical conditions in which contribute to its ecological success and ultimately to its role as an effective opportunistic pathogen. ${ }^{75}$

In our study, MRSA was in highest prevalence as compared with the other gram-positive bacteria (34.2\%), while both P. aeruginosa and A. baumannii were the commonest gram-negative bacteria (33.1\%), thus our Sulaimani health directorate must try to take high precaution about them and provide good antibiotics for their eradication.

In the present study, the incidence of gram-negative bacteria is highly statistical significant with the increasing of TBSA burnt percent $\mathrm{p}<0.001$; this mean patients with greater TBSA percent more likely to be infected with gram-negatives bacteria compared to grampositives bacteria (Table 12). This finding is in agreement with the previous study which was done by Chang, P.H. in USA. ${ }^{76}$ This may be due to inappropriate common use of broad spectrum antibiotic and increasing cross contamination of gram-negative bacteria; because of the lack of stringent infection control adherences. On the other hand, another study in USA by Barber, R.C., et al showed that gram-negative colonization is in relation with increasing TBSA burnt percent, and suggested that clinically the risk established in the biological implication of the observation, may be that reduce total pathway signaling Toll-like receptor 4 (TLR4 +896 G-allele) carriers fails to control local infection. Carriers of the G-allele at this single nucleotide polymorphism (SNP) exhibit reduced lipopolysaccharide (LPS) responsiveness as well as an increased risk for septic shock and susceptibility to Gram-negative sepsis. ${ }^{77}$

In the present study, we found that the higher incidence of gramnegative bacteria statistically significant with more prolonged hospital stays $p<0.001$ (Table 10). Inanimate environment of patient infected with gram-negative bacteria was frequently contaminated with those organisms considered a factor for infection. Another factor may be due to gram-negative bacteria characterized by making conjugation between themselves; this conjugation lead to make changes in their virulently facts to resist for more antibiotic and antiseptics. However, its ability to establish itself widely in hospital equipment's such as bed pans and medicines like lotions, ointments and eye drops and even stocks and distilled water for plants and flower. ${ }^{78}$ On the other hand patients or physician perception dosages do not complete the course of prescribed dose of antibiotic because of the blithesome effect of the control of the infection from the start of the course, it results to involving major genetic and biochemical mechanisms, bacterial transformation, hyper mutability, and plasmid mediated improvements resistant, ending with drug efflux mechanism and gaining of characters to synthesize endogenous and exogenous antibiotic degrading enzymes, because of these the gram-negative bacteria become more MDR and lead to increase patients duration of hospitalization. ${ }^{79}$

\section{Mortality}

The overall fatality rate of hospitalized children due to burn in our study was $4.7 \%$ (Table 6). This finding is consistent to the results of a study by Arslan, H., and his coaouthores $4.3 \%{ }^{43}$ It was higher than the other previous literatures from high income countries such as $1.3 \%$ in Kuwait, ${ }^{80} 0.7 \%$ in America, and $1.1 \%$ in Europe ${ }^{25}$ but was less than the result obtained by Golshan, et al in South Asia 9\%. ${ }^{81}$ An important point is that the burnt patients from other provinces treated or died as outpatients and were excluded. In addition, hospitals mortality rates are likely to be related to the quality of hospital care and case mix in terms of factors associated with mortality.

In our study, we found that burn size is the strongest predictor of death and statistically highly significant $p<0.001$ (Table 6 ); this mean patient who have greater TBSA more likely to be died rather than the patients have smaller TBSA. This finding is consistent to the previous pediatric burn studies, ${ }^{61,82} .55,54,83,84$ It is important, to report hospital mortality rate that relate to TBSA burnt. However, various studies published on burn epidemiology; reported that TBSA and its relation to mortality in different ways make comparisons difficult. ${ }^{85}$ Such differences may be due to other risk factors such as age and inhalation injury, but could also be related to differences in quality of care. As well as immature immune system and increased fluid requirement may lead to higher burn mortality rate, which place children at high risks for sepsis and hypovolemic shock after burn injury. ${ }^{3}$

In our study, flame burns were more fatal than other types of burn $65.6 \%$ and it is highly statistical significant $p<0.001$ (Table 7). It is consistent to the global WHO burns that showed fire is more fatal among pediatric populations and it records the highest mortality rate. ${ }^{25}$ The same result was seen in many of previous studies around the world. ${ }^{3,82,86-88}$ This is because of, the large proportion of the total body surface area affected among flame burn victims, in which the flame produced by flammable substance spread to wide space area of the body. As well as these patients were more prone to mortal complications especially in pediatric populations such as burn shock, acute renal failure and sepsis. ${ }^{43}$ 
Burn wound infection is a serious problem leading to death. It needs critical monitoring in pediatric burn patients. So, we found that died patients statistically significant have relation with infection $\mathrm{p}=0.007$ (Table 7); this means infection is the serious problem resulting mortality. This finding is in agreement with the most of previous studies. ${ }^{61,89,90}$ The highest level of death caused by infection is probably due to the lack of early wound swab and blood culture for bacteria and sensitivity of organism which is leading to septicemia and then death. Furthermore, a study by Ramakrishnan, M., et al showed that early management and empirical antibiotic regimes decrease wound sepsis resulting to the increase of survival. ${ }^{91}$

Despite of those, we saw that mortality rate in non-infected patients is too high (Table 7), this is because (27/38) of these dead patients' TBSA burnt was more than $40 \%$ (Table 8 ). As we mentioned about this finding before; patients with greater TBSA $\%$ were at high risk of death. According to the forensic medicine death reports, from noninfected patients who died; inhalation injury were the main factors leading to death from patients who have smaller TBSA burnt percent (of less than $40 \%$ ) (Table 8). Our result is consistent to Karimi, H., and his coauthores study [6464]. This indicates that inhalation injury seriously contributes with TBSA as a major risk for death in burn patient, especially in children.

\section{Conclusion}

Burn infection is an important cause of morbidity among burn children in hospital. Burn injuries among pediatrics in our community need to critical care and monitoring. Preschool stages and males children were at risk for burn injury. Home environment is not safe for children. Burn infection is a major issue for hospital morbidity. Our study showed that the major risks for pediatric burn infection were flame burns, long duration of hospitalization, and third/mix degree of burn. Patients with greater TBSA burnt more likely to get infection. Overall, gram-negative bacteria were the commonest pathogens followed by gram-positives and then fungi. In additional, MRSA was the commonest frequent gram-positive bacteria detected and it is the major cause for infection. Fungal and Gram-negative colonization more associated with higher TBSA burnt and prolonged hospitalization. We recommended that regular microbial surveillance of burn patient and hospital Environment microbiological surveillance of potential nosocomial pathogens indicated inanimate environment of patients should be done to find out the presences of our pathogens which are contaminated.

\section{Acknowledgements}

None.

\section{Conflict of interest}

Author declares there is no conflict of interest in publishing the article.

\section{References}

1. Elkafssaoui S, Tourabi K, Bouaiti E, et al. Epidemiological analysis of burn patients in the military hospital, Rabat, Morocco. Ann Burns Fire Disasters. 2011;24(3):115-119.

2. Dissanaike S, Rahimi M. Epidemiology of burn injuries: highlighting cultural and socio-demographic aspects. Int Rev Psychiatry. 2009;21(6):505-511.

3. Al-Zacko SM, Zubeer HG, Mohammad AS. Pediatric burns in Mosul: an epidemiological study. Ann Burns Fire Disasters. 2014;27(2):70-75.
4. Rimmer RB, Bay RC, Alam NB, et al. Measuring the burden of pediatric burn injury for parents and caregivers: informed burn center staff can help to lighten the load. J Burn Care Res. 2015;36(3):421-427.

5. Morrongiello BA, Kiriakou S. Mothers' home-safety practices for preventing six types of childhood injuries: what do they do, and why? $J$ Pediatr Psychol. 2004;29(4):285-297.

6. Mousa HA. Burn and scald injuries. East Mediterr Health J. 2005;11(5-6):1099-1109.

7. Pizano LR, Davies J, Corallo JP, et al. Critical care and monitoring of the pediatric burn patient. J Craniofac Surg. 2008;19(4):929-932.

8. Hidalgo F, Mas D, Rubio M, et al. Infections in critically ill burn patients. Med Intensiva. 2016;40(3):179-185.

9. Fekih Hassen A, Ben Khalifa S, Raddaoui K, et al. [Risk factors for nosocomial infection in pediatric burn patients]. Ann Fr Anesth Reanim. 2012;31(7-8):591-595.

10. Anlatici R, Ozerdem OR, Dalay C, et al. A retrospective analysis of 1083 Turkish patients with serious burns. Part 2: burn care, survival and mortality. Burns. 2002;28(3):239-243.

11. Barıfl ÇAKIR, Berrak. Systemic Responses to Burn Injury. Turk J Med Sci. 2004;34:215-226.

12. Stone PW, Larson E, Kawar LN. A systematic audit of economic evidence linking nosocomial infections and infection control interventions: 19902000. Am J Infect Control. 2002;30(3):145-152.

13. http://wwwcdegog/ncidod/ dhqp/healthdishtml.

14. Rastegar Lari AR, Alaghehbandan R, Akhlaghi L. Burn wound infections and antimicrobial resistance in tehran, iran: an increasing problem. Ann Burns Fire Disasters. 2005;18(2):68-73.

15. Lee JJ, Marvin JA, Heimbach DM, et al. Infection control in a burn center. J Burn Care Rehabil. 1990;11(6):575-580.

16. Raymond J, Aujard Y. Nosocomial infections in pediatric patients: a European, multicenter prospective study. European Study Group. Infect Control Hosp Epidemiol. 2000;21(4):260-263.

17. Becerra MR, Tantalean JA, Suarez VJ, et al. Epidemiologic surveillance of nosocomial infections in a Pediatric Intensive Care Unit of a developing country. BMC Pediatr. 2010;10:10:66. doi: 10.1186/1471-2431-10-66.

18. Church D, Elsayed S, Reid O, et al. Burn wound infections. Clin Microbiol Rev. 2006;19(2):403-434.

19. wwwwhoint/about/licensing/copyright_form/en/indexhtml.

20. Salehifar E, Khorasani G, Ala S. Time-related Concordance Between Swab and Biopsy Samples in the Microbiological Assessment of Burn Wounds. Wounds. 2009;21(3):84-88.

21. Pechorsky A, Nitzan Y, Lazarovitch T. Identification of pathogenic bacteria in blood cultures: comparison between conventional and PCR methods. J Microbiol Methods. 2009;78(3):325-330.

22. J. V, J. V, K. E, et al. Basic laboratory procedures in clinical bacteriology, 2nd ed. WHO Geneva; 2003;91-93.

23. Kadir A. Paediatric Burns in Sulaimani, Iraq. Ann Burns Fire Disasters. 2007;20(3):121-125.

24. Biscegli TS, Benati LD, Faria RS, et al. [Profile of children and adolescents admitted to a Burn Care Unit in the countryside of the state of Sao Paulo]. Rev Paul Pediatr. 2014;32(3):177-182.

25. World Health Organization (WHO). World report on child injury prevention. UNICEF Wa, Geneva; 2008.

26. Zhai H, Liu S, Jiang L, et al. Characteristics of 985 pediatric burn patients in the south of Liaoning province of China. Burns \& Trauma. 2014;2(3):136-140. 
27. Kramer CB, Rivara FP, Klein MB. Variations in U.S. pediatric burn injury hospitalizations using the national burn repository data. $J$ Burn Care Res. 2010;31(5):734-739.

28. Mukerji G, Chamania S, Patidar GP, et al. Epidemiology of paediatric burns in Indore, India. Burns. 2001;27(1):33-38.

29. Agbenorku P, Agbenorku M, Fiifi-Yankson PK. Pediatric burns mortality risk factors in a developing country's tertiary burns intensive care unit Int J Burns Traum. 2013;3(3):151-158.

30. Rafii MH, Saberi HR, Hosseinpour M, et al. Epidemiology of pediatric burn injuries in isfahan, iran. Arch Trauma Res. 2012;1(1):27-30.

31. Yavuz A, Ayse A, Abdullah Y, et al. Clinical and demographic features of pediatric burns in the eastern provinces of Turkey. Scand J Trauma Resusc Emerg Med. 2011;19:6

32. H S. Bacterial Profile of Paediatric Burn Wounds and their Antibacterial Sensitivity Patterns. Journal of Surgery: Open Access ( ISSN 2470-0991 ). $2016 ; 2$.

33. Gari AA, Al-Ghamdi YA, Qutbudden HS, et al. Pediatric burns in Western Saudi Arabia. Saudi Med J. 2012;33(10):1106-1110

34. Suzuki M, Aikawa N, Kobayashi K, et al. Prognostic implications of inhalation injury in burn patients in Tokyo. Burns. 2005;31(3):331-336.

35. Rajpura A. The epidemiology of burns and smoke inhalation in secondary care: a population-based study covering Lancashire and South Cumbria. Burns. 2002;28(2):121-130.

36. Droussi H, Benchamkha Y, Ouahbi S, et al. Epidemiology and treatmen of paediatric burns in a large children's hospital in Morocco: Analysi of 394 cases. African Journal of Emergency Medicine. 2013;3:110-115.

37. Schneider JC, Nadler DL, Herndon DN, et al. Pruritus in pediatric burn survivors: defining the clinical course. J Burn Care Res. 2015;36(1):151-158

38. Achamyelesh T. Magnitude, Clinical Presentation, and Outcome of Pediatric Burn Injuries at Yekatit 12 Hospital, Addis Ababa, Ethiopia; 2014

39. Chalya PL, Mabula JB, Dass RM, et al. Pattern of childhood burn injuries and their management outcome at Bugando Medical Centre in Northwestern Tanzania. BMC Res Notes. 2011;4:485.

40. Xin W, Yin Z, Qin Z, et al. Characteristics of 1494 pediatric burn patients in Shanghai. Burns. 2006;32(5):613-618.

41. Mahmood. HJ, Ibraim. DRH. Prevalence of Burn in children under (15) years in Mosul City (2009, 2010). 2014;2(2)

42. Ren G, Tianxing C, Jingxiang Y, et al. Ten-Year Review of Pediatric Burn Hospitalizations in Southern Taiwan at a Burn Unit: Epidemiology and Changing Trends = within a single decade pediatric burn center in southern Taiwan burns epidemiology and changing trends in inpatien retrospective analysis. J Taiwan Plastic Surgery Medical Association 2014;23(2):140-148.

43. Arslan H, Kul B, Derebasinlioglu H, et al. Epidemiology of pediatric burn injuries in Istanbul, Turkey. Ulus Travma Acil Cerrahi Derg 2012;19(2):123-126.

44. Karimi H, Motevalian SA, Rabbani A, et al. Prediction of mortality in pediatric burn injuries: R-baux score to be applied in children (pediatricsbaux score). Iran J Pediatr. 2013;23(2):165-170.

45. Uygur F, Sahin C, Duman H. Analysis of pediatric burns in a tertiary burns center in istanbul, Turkey. Eur J Pediatr Surg. 2009;19(3):174-178.

46. Kurane SB, Ugane S. A retrospective study of pediatrics burns at general hospital in rural India. Int JMed Sci Public Health. 2014;3(10):1235-1237.
47. Alharthy N, Al Mutairi M, AlQueflie S, et al. Pattern of burns identified in the Pediatrics Emergency Department at King Abdul-Aziz Medical City: Riyadh. Journal of Natural Science, Biology and Medicine. 2016;7(1):16-21.

48. Hammoudi AA. Association of Pathogenic Bacterial Isolates in Burn Wound Infections. Medical Journal of Babylon ثيبطل اب نل 2014;11(1):52-57.

49. Barret JP, Herndon DN. Effects of burn wound excision on bacterial colonization and invasion. Plast Reconstr Surg. 2003;111(2):744-750.

50. Erol S, Altoparlak U, Akcay MN, et al. Changes of microbial flora and wound colonization in burned patients. Burns. 2014;30(4):357-361.

51. Nasser S, Mabrouk A, Maher A. Colonization of burn wounds in Ain Shams University Burn Unit. Burns. 2003;29(3):229-233.

52. Karami Matin B, Rezaei S. Epidemiological Analysis and Cost of Hospitalization Associated with Pediatric Burns in Kermanshah, Iran International Journal of Pediatrics. 2014;2(4.3):369-376.

53. Parbhoo A, Louw QA, Grimmer-Somers K. A profile of hospitaladmitted paediatric burns patients in South Africa. BMC Research Notes. 2010;DOI: $10.1186 / 1756-0500-3-165$.

54. Tekin R, Yolbas I, Selcuk CT, et al. An evaluation of pediatric burn patients over a 15-year period. Ulus Travma Acil Cerrahi Derg. 2012;18(6):514-518

55. Peddi M, Segu S, Ramesha K. The persistent paradigm of pediatric burns in India: An epidemiological review. Indian Journal of Burns. 2014;22(1):93-97.

56. Mohamed El-Maghawry HAM, Nem WE, Sherif N-A, et al. An interventional study to decrease healthcare associated burn wound infections in the burn unit of Al Ahrar Hospital in Zagazig city, Sharkia Governorate. International Journal of Current Microbiology and Applied Sciences. 2016;5:566-578

57. Kramer L. Third Degree Burns and Infection. Burn Injury Resource Center, USA; 2012.

58. Cohen AD, Gurfinkel R, Glezinger R, et al. Pediatric Burns in the Bedouin Population in Southern Israel. The Scientific World JOURNAL. 2007; 7:1842-18477.

59. Liwimbi OM, Komolafe IO. Epidemiology and bacterial colonization of burn injuries in Blantyre. Malawi Med J. 2007;19(1):25-27.

60. Mayhall CG. The epidemiology of burn wound infections: then and now. Clin Infect Dis. 2003;37(4):543-550.

61. Rosanova MT, Stamboulian D, Lede R. Risk factors for mortality in burn children. Braz J Infect Dis. 2014;18(2):144-149.

62. Behzadnia S, Davoudi A, Rezai MS, et al. Nosocomial infections in pediatric population and antibiotic resistance of the causative organisms in north of iran. Iran Red Crescent Med J. 2014;16(2):e14562.

63. Duke J, Wood F, Semmens J, et al. A study of burn hospitalization for children younger than 5 years of age: 1983-2008. Pediatrics. 2011;127(4):e971-977.

64. Karimi H, Montevalian A, Motabar AR, et al. Epidemiology of paediatric burns in Iran. Ann Burns Fire Disasters. 2012;25(3):115-120.

65. A. R, C. T, J. C, et al. Infection in Burn Patients. Annals of the MBC 1992;5:2.

66. Milenkovic M, Russo A, AnneElixhauser. Hospital Stays for Burns 2004. Agency for Healthcare Research and Quality. USA; 2007.

67. Ghai S, Sachdeva A, Mahajan R, et al. Bacteriological and Antibiotic Susceptibility Profile of Aerobic Burn Wound Isolates at a Tertiary Care Institute in Northern India. Journal of Applied \& Environmental Microbiology. 2015;3(4):95-100. 
68. Branski LK, Al-Mousawi A, Rivero H, et al. Emerging infections in burns. Surg Infect (Larchmt). 2009;10(5):389-397.

69. Weber J, McManus A. Infection control in burn patients. Burns. 2004;30(8):A16-24.

70. Imran M, Faheem M, Aslam V, et al. Wound infections and culture sensitivity pattern in pediatric burn patients. Journal of Postgraduate Medical Institute (Peshawar-Pakistan). 2011;23(4).

71. Dormanesh B, Siroosbakhat S, Khodaverdi Darian E, et al. MethicillinResistant Staphylococcus aureus Isolated From Various Types of Hospital Infections in Pediatrics: Panton-Valentine Leukocidin, Staphylococca Chromosomal Cassette mec SCCmec Phenotypes and Antibiotic Resistance Properties. Jundishapur J Microbiol. 2015;8(11):e11341.

72. Ladhani S, Garbash M. Staphylococcal Skin Infections in Children. Pediatric Drugs. 2005;7(2):77-102.

73. Guggenheim M, Zbinden R, Handschin AE, et al. Changes in bacterial isolates from burn wounds and their antibiograms: a 20-year study (1986-2005). Burns. 2009;35(4):553-560.

74. Ergun O, Celik A, Ergun G, et al. Prophylactic antibiotic use in pediatric burn units. Eur J Pediatr Surg. 2004;14(6):422-426.

75. Paranjothi S, Dheepa R. Screening for multidrug resistance bacteria Pseudomonas aeruginosa in hospitalized patients in Hosur, Krishnagir (dt). International Journal of Pharma and Bio Sciences. 2010;1(3):1-15.

76. Chang PH. Increasing Incidence of Multiple Drug Resistant Gram Negative Bacteria in a Pediatric Burn Population. academic surgical congress abstracts. USA; 2016.

77. Barber RC, Aragaki CC, Rivera-Chavez FA, et al. TLR4 and TNF-alpha polymorphisms are associated with an increased risk for severe sepsis following burn injury. J Med Genet. 2004;41(11):808-813.

78. Vinitha C, Tiwari P, Singh S, et al. Pattern and Extent of Hospital Acquired Wound Infections in Burns Patients in a Delhi Tertiary Care Hospital. Indian journal of preventive and social medicine. 2011;42(1):79-81.

79. Nayak N, Lenka RK, Padhy RN. Surveillance of multidrug resistant suppurative infection causing bacteria in hospitalized patients in an Indian tertiary care hospital. Journal of Acute Disease. 2014;3:148-156.
80. Sharma PN, Bang RL, Al-Fadhli AN, et al. Paediatric burns in Kuwait: incidence, causes and mortality. Burns. 2006;32(1):104-111.

81. Golshan A, Patel C, Hyder AA. A systematic review of the epidemiology of unintentional burn injuries in South Asia. $J$ public health. 2013;35(3):384-396.

82. Labib JR, Shalaby SF. Epidemiology and Outcomes of Pediatric Burn Injuries in Cairo University Hospital- Egypt. British Journal of Medicine \& Medical Research. 2014;4(4):1056-1068

83. Priyadarshini S, Kumar P, Devi ES, et al. Epidemiology and profile of pediatric burns- a retrospective review. Journal of Society for Wound Care \& Research. 2015;8(1):2229-3221.

84. Kraft R, Herndon DN, Al-Mousawi AM, et al. Burn size and survival probability in paediatric patients in modern burn care: a prospective observational cohort study. Lancet. 2012;379(9820):1013-1021.

85. Othman N. Epidemiology of burn injuries in Sulaymaniyah province of Iraq. (Thesis). University of Nottingham. UK; 2010.

86. Karimi H, Motevalian SA, Momeni M, et al. Etiology, Outcome and Mortality Risk Factors in Children Burn. Surgical Science. 2015;06:42-49.

87. Wolf SE, Rose JK, Desai MH, et al. Mortality determinants in massive pediatric burns. An analysis of 103 children with $>$ or $=80 \%$ TBSA burns ( $>$ or $=70 \%$ full-thickness). Ann Surg. 1997;225(5):554-565. discussion $565-559$.

88. Fadeyibi IO, Mustapha IA, Ibrahim NA, et al. Characteristics of paediatric burns seen at a tertiary centre in a low income country: a five year (2004-2008) study. Burns. 2011;37(3):528-534.

89. Alp E, Coruh A, Gunay GK, et al. Risk factors for nosocomial infection and mortality in burn patients: 10 years of experience at a university hospital. J Burn Care Res. 2012;33(3):379-385.

90. Sheridan RL. Sepsis in pediatric burn patients. Pediatr Crit Care Med. 2005;6(3):S112-119.

91. Ramakrishnan M, Ravikumar K, Ravikumar K, et al. Management of acute complications of pediatric burns - our experience of 7 years. Indian Journal of Burns. 2015;23(1):12-18. 